\title{
Mixtures of non-polar molecules
}

\author{
Findlay L. Swinton \\ University of Ulster, Coleraine, Northern Ireland.
}

\begin{abstract}
The present status of the theoretical interpretation of the thermodynamic properties of mixtures of non-polar molecules is reviewed briefly. It is concluded that the equation of state and hence the phase behaviour of mixtures containing only pseudo-spherical molecules is reasonably well understood, but that current theories fail badly when applied to mixtures containing either rigid non-spherical molecules or non-spherical flexible molecules with considerable degrees of internal rotation. New experimental results on mixtures of the former type are presented including the principal excess functions of 2-butyne, 2,4-hexadiyne or trans-1,3,5-hexatriene mixed with either cyclohexane or tetrachloromethane. Experimental investigations of binary mixtures containing small flexible molecules include the measurement of the equimolar excess volumes of seventeen isomeric octanes mixed with cyclohexane and of the upper critical solution temperatures of these same octanes mixed with methanol. The pitzer conformational partition function $\mathrm{Z}$, was calculated for each octane, but no satisfactory correlation could be detected between $\mathrm{Z}$ and the experimental mixing properties.
\end{abstract}

\section{INTRODUCTION}

In 198\%, the authors of the Third Edition of Liquids and Liquid Mixtures (ref. 1) claimed that, "The theory of the equilibrium properties of liquid mixtures, like that of pure liquids, is now an essentially solved problem. By this assertion we mean that for any arbitrarily chosen set of intermolecular potentials it is now possible to calculate the thermodynamic properties, with adequate accuracy, by using one of several statistical mechanical theories." Support for this statement lay in the excellent agreement between the Monte Carlo and molecular dynamics computer-generated "experimental" low-pressure excess functions and high-pressure phase diagrams of model mixtures with known intermolecular potentials and the theoretical values calculated using perturbation theory and the simpler van der Waals one- and two-fluid models. The agreement is at its best for mixtures containing molecules of comparable energy and size and is less than perfect for mixtures containing highly dipolar molecules and for mixtures where the species are greatly dissimilar in size.

Since 1982 experimental and theoretical advances have been made by several groups, particularly the Calado, Gubbins, Staveley and Streett co-operative who have measured the thermodynamic properties of a carefully selected series of binary mixtures. These mixtures are composed of simple molecules containing but few atoms and the binary mixtures are selected to cover a whole range of mixture types, spherical + dipolar, spherical + quadrupolar, spherical + hydrogen bonded, etc. The experimental results have been analysed using perturbation theory and successful agreement has been achieved in the majority of cases. Up-to-date reviews of this field are given elsewhere in this Symposium particularly in the papers of Gubbins, staveley and streett.

Successful though this type of approach is, a major problem is that, by using perturbation theory of this degree of sophistication, each separate analysis is time consuming and the prediction of the thermodynamic properties of other, related mixtures cannot yet be achieved on a routine basis. The principal problem once again, is the difficulty of establishin a adequate forms of the intermolecular potentials. 
For several decades, chemical engineers, operating at a less sophisticated, but more utilitarian, level have employed a variety of empirical analytic equations of state, several of which have excellent predictive powers, especially when combined with computer-based data banks containing the relevant physical properties of the pure components. These equations range from simple cubic equations such as the Soave-Redlich-Kwong (rei. c c) and PengRobinson ( $r e f .3$ ) to much more elaborate and multi-constant equations such as the Benedict-Webb-Rubin-Starling (ref. 4). An excellent review of this whole field is that of Gibbons (ref. 5 ).

There is another group of analytic equations of state which can more properly be said to have a firm theoretical base and which can reproduce accurately the computer-generated hard sphere properties of both pure liquids and mixtures. When an attractive van der Waals term is added (ref. 6) such equations can represent the experimental thermodynamic properties of mixtures of real fluids composed of pseudo-spherical, non-polar molecules with excellent precision. Such analyses have been undertaken by McGlashan (ref. 7), Marsh ( ref. 8) and Blinowska et al. (ref.9). Typical of the more successful of such equations is that of Carnahan and Starling (ref. 10) which, with the attractive term added, can be written

$$
\frac{\mathrm{pV}}{\mathrm{RT}}=\frac{1+\mathrm{y}+\mathrm{y}^{2}-\mathrm{y}^{3}}{(1-\mathrm{y})^{3}}-\frac{\mathrm{a}}{\mathrm{RTV}}
$$

where $\mathrm{y}=\mathrm{b} / \mathrm{V}$ and $\mathrm{b}$ is the actual volume of the molecules, $\mathrm{b}=\pi N \sigma^{3} / 6$ if the molecules are spheres of diameter $\sigma$, $V$ is the molar volume and $N$ the Avogadro constant. $\sigma$ and $a$, the attractive constant, can be calculated from pairs of pure substance molecular properties typically the gas-liquid critical constants or liquid state parameters such as the molar volume and enthalpy of vaporization. An elaboration of this approach is to treat these two parameters as functions of temperature (ref.9). Application of these equations to mixtures requires the estimation of one or two adjustable parameters $\xi$ and $k$, which represent deviations of the unlike pair potential from the Lorentz-Berthelot combining rules

$$
\begin{aligned}
& a_{12}=\xi\left(a_{11} \cdot a_{22} \cdot b_{12}^{2} / b_{11} \cdot b_{22}\right)^{\frac{1}{2}} \\
& b_{12}=k\left[\left(b_{11}^{\frac{1}{3}}+b_{22}^{\frac{1}{3}}\right) / 2\right]^{3}
\end{aligned}
$$

Another equation-of-state treatment which has been applied successfully to mixtures of non-polar or weakly-polar hydrocarbons in particular is that of Patterson (ref. 11). Patterson has adapted the corresponding states theory of Prigogine and Flory (ref. 12) to such mixtures. The two pure substance parameters required are usually the thermal pressure coefficient, $\gamma_{v}$ and the coefficient of thermal expansion $\alpha_{p}$. A minor problem which reduces the range of applicability of this treatment is that, whereas good experimental values of $\alpha_{p}$ are known for many hundreds of pure substances, $\gamma_{v}$ values are much rarer and are relatively difficult to measure. A review of the current status of this approach is given by a paper by Patterson in this Symposium.

Finally mention should be made of group contribution methois as representing a totally different approach to the prediction of the properties of liquid mixtures. Semi-empirical in concept and utilitarian in design such schemes based on UNIFAC (ref. 13), ASOG (ref. 14) and the like have now reached a high level of sophistication (ref. 15) and, in association with computerbased clata banks, are capable of predicting the activity coefficients and hence the phase behaviour and distillation characteristics of a wide variety of multi-component mixtures, although only under a restricted set of physical conditions. The prime disadvantage is that, because all such theories are essentially interpolative and have no rigorous statistical mechanical basis, they are unable to represent the properties of systems at temperatures and pressures well removed from the conditions under which the pure substance and binary mixture input data were collected. Even with these severe restrictions such theories have an enthusiastic following although the present author is constantly reminded of Abraham Lincoln's celebrated book review, "People who like this sort of thing will find this is the sort of thing they like!"

With this brief preamble, the rest of this contribution is concerned with two types of liquid mixture whose interpretation still poses problems for current theory. These are mixtures containing non-spherical, non-dipolar molecules and mixtures containing, as one component, one of a series of isomeric, flexible hyärocarbons. 


\section{Mixtures containing rigid linear molecules}

The experimental work of patterson and his co-workers mentioned in the previous section has concentrated or mixtures of aliphatic and alicyclic hydrocarbons where the pseudo-linear molecules useá, typically the $n-a l k a n e s$, possess considerable degrees of flexibility. Although there is good evidence from depolarized light scattering that such molecules undergo some local ordering and mutual alignment in the pure state, the n-alkanes cannot be considered to be ideal models of rigid rods and currently the iniluence of intra-molecular flexing and rotation on the thermodynamic properties of both pure substances and nore particularly on mixtures is not well understood.

The alkyne series provide real molecular systems that closely approximate to true rigid sphero-cylinders and this shape is particularly amenable to theoretical treatment. The two molecules 2-butyne and $\tilde{z}, 4$-hexadiyne were selected because they are reasonably stable substances which are readily available commercially. Thermodynamic measurements were also made on trans-1,3,5-hexatriene. Although this molecule can undergo a certain degree of internal rotation, the conjugated system increases the rotational barriers and there is a high probability that the molecule will exist for much of the time in the fully extended state. An experimental disadvantage is that such trienes are unstable in the presence of oxygen and so all sample handling must be conducted in a nitrogen-filled glove box. z-butyne and trans-1,3,5hexatriene are liquid at room temperature but 2,4 -hexadiyne is a solid melting at $341 \mathrm{~K}$. This latter substance has by far the highest melting temperature of any $\mathrm{C}_{6}$ hydrocarbon and this is evidence of strong intermolecuiar quadrupole-quadrupole forces in the pure substance with the likelihood that the liquid state is also highly ordered. Experimental evidence for this latter supposition was sought using depolarized Rayleigh light scatterirg. expression

$\mathrm{g}_{2}$, the second rank orientational parameter is given by the

$$
\mathrm{g}_{2}=1+\sum_{i \neq 1}\left\langle 3 \cos ^{2} \theta_{1 i}-1\right\rangle / 2
$$

where $\theta_{1 i}$ is the relative orientation of a pair of molecules. $g_{2}$ is a measure of the correlation of molecular orientations in the condensed phase where, for linear sphero-cylindrical molecules, $\mathrm{g}_{2}>1$ indicates an enhancea parallel orientation of the molecular axes. This function can be measurea in several different ways and the one adopted involves measuring the concentration dependence of the depolarized Rayleigh intensity as the anisotropic fluid is diluted, ideally with a wholly-isotropic solvent (ref. 16). Subsidiary experiments must be carried out to correct for depolarized scattering due to collisional effects. Up to one third of the total depolarized intensity from even highly anistropic liquids can be due to collisional processes. The total intensity measurements are correcteci by measuring the line shape of the scattered spectrum and estimating the relative intensities due to the two processes. This separation can be achieved relatively easily, for the collective reorientational motions give rise to a narrow central line, usually Lorentzian in shape, that is superimposed upon a much broader exponential line due to molecular collisions.

The legitimacy oî the dilution experiment has been rightly criticized (reí. 17 ) on the grounds that large errors occur in the derived $\mathrm{g}_{2}$ values when the refractive indices of the anisotropic scatterer and the near-isotropic solvent difier by a large amount, typically if $\Delta \mathrm{n}>0.1$. This was not the case for the three acetylinic molecules studied as is shown in Table 1 where the experimental values for $g_{2}$ are listed for 2-butyne, 2,4-hexadiyre and also for 3,5-octadiyne. Light scattering measurements could not be undertaken on trans-1,3,5-hexatriene due to decomposition that occurred when this material was exposed to the intense argon ion laser beam used in the light scattering photometer. Also listed in Table 1 are $\mathrm{g}_{2}$ values for benzene, hexafluorobenzene and carbon disulphide where the figures in brackets are the measurements oi Battaglia et ai. (ref. it) obtained using a combination of the depolarized Rayleigh spectrum and Cotton-Mouton measurements. This technique avoids the uncertainties associated with the dilution method and are thus more reliable. In Table 1 the data for $\varepsilon, 4$-hexadiyne are measured just above the melting temperature at $343 \mathrm{~K}$ whereas all other values were obtained at $298 \mathrm{~K}$.

Orientational correlations are seen to be present in all listed molecules but are particularly evident in the diynes and in hexafluorobenzene. These measurements give weight to the intuitive supposition that the rod-like 


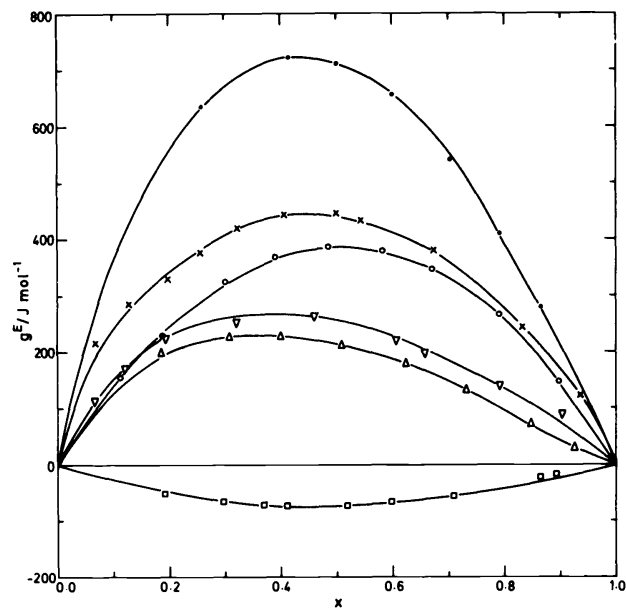

Fig. 1. Molar excess Gibbs functions for $\bullet$, 2,4-hexadiyne + cyclohexane and $\Delta, 2,4$-hexadiyne + tetrachloromethane at $343.15 \mathrm{~K}$ and for $\circ, 2$-butyne + cyclohexane; $\square, 2$-butyne + tetrachloromethane; $x, \operatorname{trans}-1,3,5$-hexatriene + cyclohexane; $\nabla$, trans; $1,3,5-$ hexatriene + tetrachloromethane, all at $298.15 \mathrm{~K} . \quad x$ is the mole fraction of the anisotropic component.

TABLE 1. Refractive index differences $\Delta \mathrm{n}$ between the listed substance ard the cyclohexane solvent and $\mathrm{g}_{2}$, the orientational correlation function.

\begin{tabular}{llc}
\hline Substance & $\Delta \mathrm{n}$ & $\mathrm{g}_{2}$ \\
\hline 2-butyne & 0.031 & 1.20 \\
2,4-hexadiyne & 0.080 & 2.31 \\
3,5-octadiyne & 0.071 & 3.97 \\
hexafluorobenzene & 0.049 & $2.58(2.92)$ \\
benzene & 0.071 & $(1.45)$ \\
carbon disulphide & 0.205 & $(1.37)$ \\
& & \\
\hline
\end{tabular}

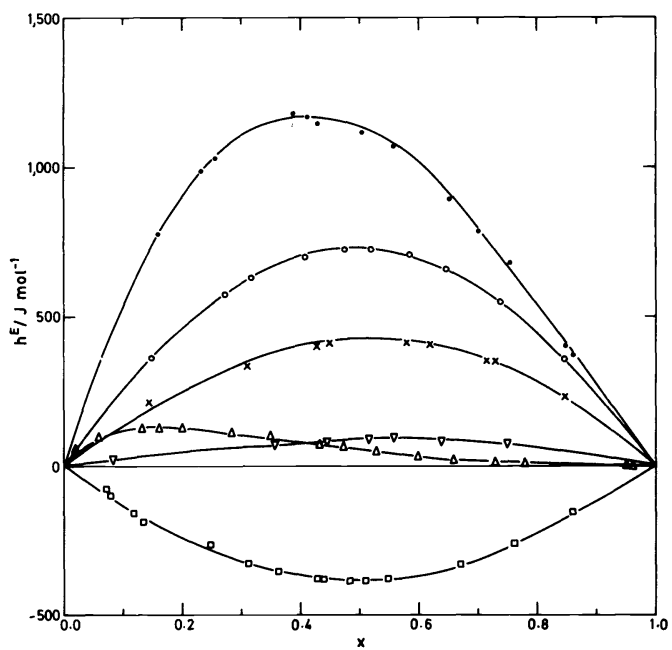

Fig. 2. Molar excess enthalpies, symbols as in Fig. 1.

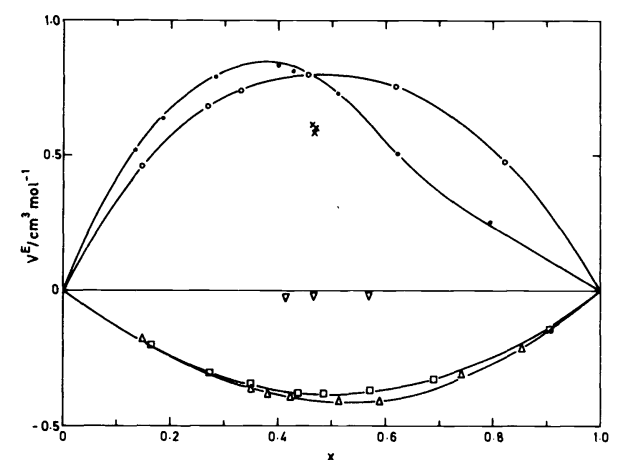

Fig. 3. Molar excess volumes, symbols as in Fig. 1.

TABLE 2. Equimolar excess functions for pseudo-spherical + linear mixtures.

\begin{tabular}{|c|c|c|c|c|c|}
\hline Mixture & $\mathrm{T} / \mathrm{K}$ & $\mathrm{g}^{\mathrm{E}} / \mathrm{J} \mathrm{mol}^{-1}$ & $\mathrm{~h}^{\mathrm{E}} / \mathrm{J} \mathrm{mol}^{-1}$ & $\mathrm{Ts}^{\mathrm{E}} / \mathrm{J} \mathrm{mol}{ }^{-1}$ & $\mathrm{v}^{\mathrm{E}} / \mathrm{cm}^{3} \mathrm{~mol}^{-1}$ \\
\hline$c-\mathrm{C}_{6} \mathrm{H}_{12}+\mathrm{C}_{4} \mathrm{H}_{6}$ & 298 & 388 & 727 & 339 & 0.81 \\
\hline $\mathrm{CCl}_{4}+\mathrm{C}_{4} \mathrm{H}_{6}$ & 298 & -73 & -387 & -314 & -0.38 \\
\hline$c-\mathrm{C}_{6} \mathrm{H}_{12}+\mathrm{C}_{6} \mathrm{H}_{8}$ & 298 & 450 & 413 & $-\quad 37$ & 0.60 \\
\hline $\mathrm{CCl}_{4}+\mathrm{C}_{6} \mathrm{H}_{8}$ & 298 & 255 & 84 & -171 & -0.02 \\
\hline$c-\mathrm{C}_{6} \mathrm{H}_{12}+\mathrm{C}_{6} \mathrm{H}_{6}$ & 343 & 713 & 1120 & 407 & 0.74 \\
\hline $\mathrm{CCl}_{4}+\mathrm{C}_{6} \mathrm{H}_{6}$ & 343 & 213 & 55 & -160 & -0.42 \\
\hline
\end{tabular}

diynes adopt a parallel alignment of the molecular axes in the fluid state whereas there is a ciegree of layering of the plate-like hexafluorobenzene molecules under similar conditions. Care must be taken not to interpret such data as indicating the direct alignment of nearest neighbours. Molecular dynamics calculations have shown ( $r e f .18$ ) that $\mathrm{g}_{2}$ is determined by the orientational correlation of a central molecule with neighbours located in a volume extending over several molecular diameters.

The principal molar excess functions of mixing, $\mathrm{g}^{\mathrm{E}}$, the excess Gibbs function, $\mathrm{h}^{\mathrm{E}}$, the excess enthalpy and $\mathrm{v}^{\mathrm{E}}$, the excess volume have been measured for the six binary mixtures of 2 -butyne, 2,4-hexadiyne and trans-1,3,5-hexatriene each with cyclohexane and with tetrachloromethane. The measurements involving 2,4-hexadiyne were made at $343.15 \mathrm{~K}$, the others at $298.15 \mathrm{~K}$. The results are illustrated as functions of $x_{1}$, the mole fraction of the anisotropic component in Fig. 1, Fig. 2 and Fig. 3 and the equimolar values of $\mathrm{gE}^{\mathrm{E}} \mathrm{hE}, \mathrm{VE}$ and also TsE are listed in Table 2 . 
An intersystem comparison reveals several common patterns. In every case the excess function for the linear component mixed with tetrachloromethane is much more negative than the functior. for the same substance mixed with cyclohexane. The magnitude of this decrease is very comparable for the mixtures containing the alkynes but is nuch less for the two mixtures containing the triene. The concentration dependence of the excess functions of the two mixtures containing, 2,4hexadiyne exhibits a considerable degree of skewing towards mixtures rich in the pseudo-spherical solvent but the excess function o ${ }^{3}$ all the other mixtures are reasonably symmetric about the equimolar composition.

There is good spectroscopic evidence that mixtures of tetrachloromethane with unsaturated hydrocarbons, including aromatics, form weak intermolecular complexes in the liquid and solid states (ref. 19) and the present results lend weight to this view. The large exothermal excess enthalpy for 2-butyne + tetrachloromethane with an equimolar value of $-387 \mathrm{~J} \mathrm{~mol}^{-1}$ is comparable with Wóycicki's figure of $-514 \mathrm{~J} \mathrm{~mol}^{-1}$ for 3 -hexyne + tetrachloromethane (ref. 20).

The six binary mixtures described above represent useful test systems against which to assess current and future statistical treatments of mixtures containing non-spherical molecules. Some physical properties of the pure substances are listed in Table 3 where it is seen that the molar volumes o $\hat{i}$ several of the pairs, typically 2,4-hexadiyne $\left(100.67 \mathrm{~cm}^{3} \mathrm{~mol}^{-1}\right)$ and tetrachloromethane (102.83 $\mathrm{cm}^{3} \mathrm{~mol}^{-1}$ ) are near identical and so overall size differences should not present a problem.

In recent years Boublik, Nezbeda and co-workers have developed severai comparable equations of state that are applicable to systems composed of hard convex bodies including spherocylinders (refs. 21, 22). These equations well reproduce the results of computer simulation experiments on such fluids. The Nezbeda equation is one of the most successful of these explicit equations and, with a van der Waals attractive term added, can be written

$$
\mathrm{pV} / \mathrm{RT}=\left[1+(3 \alpha-2) \mathrm{y}+\left(\alpha^{2}+\alpha-1\right) \mathrm{y}^{2}-\alpha(5 \alpha-4) \mathrm{y}^{3}\right] /(1-\mathrm{y})^{3}-\mathrm{a} / \mathrm{RTV}
$$

Here $\alpha=\gamma(\gamma+1) /(3 \gamma-1)$ where $\gamma$ is the overall length to breadth ratio of the spherocyclindrical molecule and $y$ has the same meaning as before. When the spherocylinder is reduced to a sphere, then $\gamma=\alpha=1$ and equation 5 becomes identical to the Carnahan and Starling equation with the added attractive term, equation 1. Pavlicek et al. ( ref. 23) have extended equation 5 to mixtures of rigid convex molecules of differing shapes anc the work of Boublik (ref. 24 ) enables expressions for the excess functions of such mixtures to be obtained. An estimate of the influence of molecular shape on the excess functions can be seen in Fig. 4. Here the molecular parameters $\sigma$ and a, for the pure fluids have been estimated from the liquid state parameters $\Delta \mathrm{H}_{\mathrm{V}}^{\circ}$ and $\mathrm{V}_{\mathrm{m}}^{\circ}$ with $\Delta \mathrm{H}_{\mathrm{V}}^{\circ}=30 \mathrm{~kJ} \mathrm{~mol}^{-1}$ and $\mathrm{V}_{\mathrm{m}}^{\circ}=100 \mathrm{~cm}^{3} \mathrm{~mol}^{-1}$ in each case. Two mixtures are considered, one with $\gamma_{1}=1$ (spherical) and $\gamma_{2}=2$, the other with $\gamma_{1}=1$ and $\gamma_{2}=3$. The projections of the shapes of the three molecular types are illustrated in Fig. 4. Qualitatively at least the curves of the excess functions have the correct sign and magnitude, with the destruction of the orientational correlations in the pure anisotropic fluid by the additon of the isotropic spherical diluent leading to positive contributions to all of the principal excess functions, including the excess entropy. The magnitude increases with the degree of elongation of the anisotropic component.

When this equation was tested against the experimental results of the six binary mixtures listed in Table 2 the outcome was decidedly disappointing. The pure substance parameters a and $\sigma$ were obtained from the liquid state properties given in Table $3, \gamma$ was set equal to 1 for cyclohexane and for 


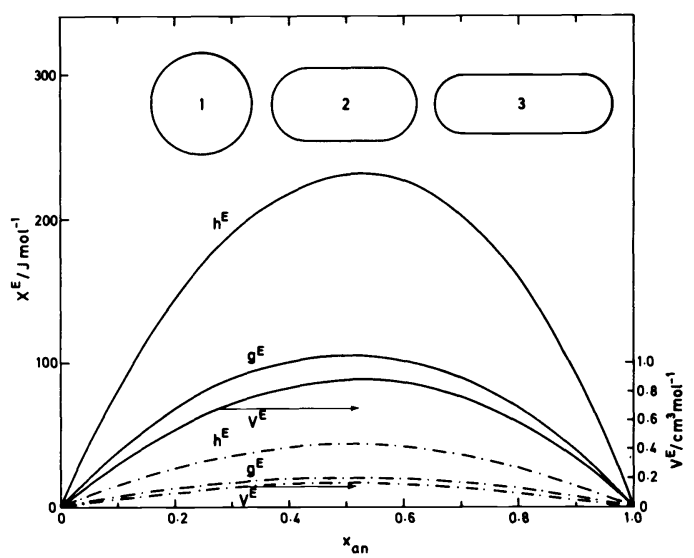

Fig. 4. Excess functions for model systems obeying the Nezbeda equation of state (refs. 22, 23, 24).....-, functions for $\gamma_{1}=1, \gamma_{2}=2$; , functions for $\gamma_{1}=1, \gamma_{2}=3$.

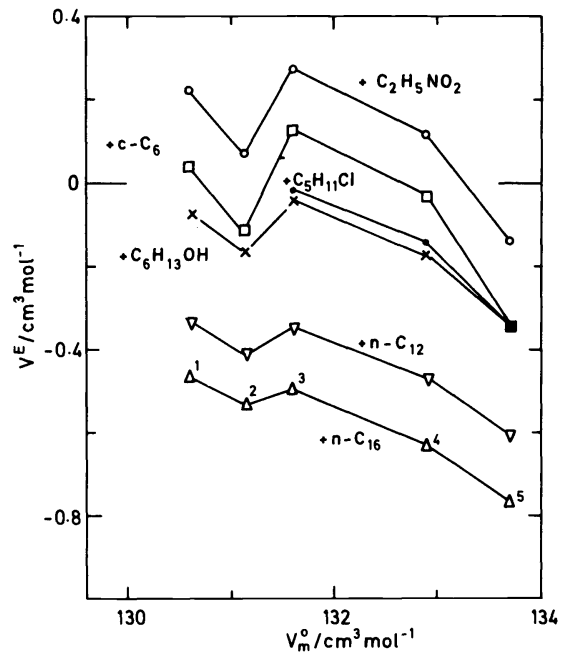

Fig. 5. Equimolar excess volumes at $298.15 \mathrm{~K}$ for mixtures of the five isomeric hexanes, 1, 3-methylpentane; 2, 2,3-dimethylbutane; 3 , n-hexane; 4 , 2-methylpentane; 5, 2,2-dimethylbutane, mixed with $\Delta, \mathrm{n}$-hexadecane; $\nabla, \mathrm{n}$-dodecane; $x, 2$-methyl-1-pentanol; $\bullet, 1$-chloropentane; $\square$, cyclohexane; o, nitroethane versus $V_{m}^{\circ}$, the molar volume of the hexanes.

tetrachloromethane, $\gamma=2$ for 2-butyne and trans-1,3,5-hexatriene and $\gamma=3$ for 2,4-hexadiyne. The only adjustable parameter used was $\xi$ which was adjusted to give an exact fit with the theoretical and experimental equimolar excess enthalpy. For all six mixtures, the simple Carnahan and Starling equation $(\gamma=1$ for both components) was found to give reasonable predictions, of the other excess functions whereas use of the Pavlicek, Nezbeda, Boublik equation (ref. 23) worsens the predictions in all cases. This lack of agreement is at a maximum for the two mixtures containing 2,4-hexadiyne and this is illustrated in Table 4 .

It may well be that adding a simple van der Waals attractive term that is, in effect, spherically symmetric in its action, to an equation that accourts for angle dependent repulsive forces is too naive and is perhaps unjustifiable. It is certainly true that the attractive part of the intermolecular potential in the vicinity of a strongly quadrupolar molecule such as 2,4 -hexadiyne will be highly orientational dependent and the derivation of a simple analytic equation of state for such a situation remains a problem for the future.

\section{Mixtures containing isomeric hydrocarbons}

Another class of liquid mixture which poses problems for theoretical analysis and interpretation is that where a common component is mixed with a series of isomeric hydrocarbons. Scott and his coworkers (ref. ¿ 6 ) were among the first to observe that a regular pattern was observed for both the excess enthalpy and, more particularly, the excess volume for such series and some typical results are illustrated in Fig. 5 where the equimolar excess volumes of the

TABLE 4. Comparison of the predictions of the Carnahan and Starling (CS) and the Pavlicek, Nezbeda and Boublik (PNB) equations of state with the experimental excess functions at $343.15 \mathrm{~K}$.

\begin{tabular}{|c|c|c|c|c|}
\hline Equation & $\xi$ & $\mathrm{h}^{\mathrm{E}} / \mathrm{J} \mathrm{mol}^{-1}$ & 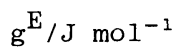 & $\mathrm{v}^{\mathrm{E}} / \mathrm{cm}^{3} \mathrm{~mol}^{-1}$ \\
\hline \multicolumn{5}{|c|}{2,4 -hexadiyne + cyclohexane } \\
\hline $\begin{array}{l}\text { Experimental } \\
\text { CS } \\
\text { PNB }\end{array}$ & $\begin{array}{c}-\overline{9} \\
0.958 \\
0.978\end{array}$ & $\begin{array}{l}1120 \\
1120 \\
1120\end{array}$ & $\begin{array}{l}713 \\
787 \\
573\end{array}$ & $\begin{array}{l}0.74 \\
0.75 \\
1.91\end{array}$ \\
\hline \multicolumn{5}{|c|}{2,4 -hexadiyne + tetrachloromethane } \\
\hline $\begin{array}{l}\text { Experimental } \\
\text { CS } \\
\text { PNB }\end{array}$ & $\begin{array}{l}-\overline{9} \\
0.999 \\
1.0165\end{array}$ & $\begin{array}{l}55 \\
55 \\
55\end{array}$ & $\begin{array}{r}213 \\
70 \\
-\quad 78\end{array}$ & $\begin{array}{r}-0.42 \\
-0.23 \\
0.64\end{array}$ \\
\hline
\end{tabular}


five isomeric hexanes $\mathrm{C}_{6} \mathrm{H}_{14}$, mixed with six difierent liquids, both hydrocarbons and non-hydrocarbons are plotted, for convenience only, against the molar volume of the pure hexanes (refs. 26-28). Within a series the pattern is uniform and a molecular explanation for this regularity is still undetermined.

Smoother, near linear plots are obtained when such data are plotted against other functions such as the solubility parameter of the hexane (ref. 28 ) and there is often a reasonable correlation when one excess function is plotted against another. Tra Van and Patterson (ref. 29) and others (ref. 27 ) have found acceptable agreement with the experimental $\mathrm{v}^{\mathrm{E}}$ values for hexanes $+\mathrm{n}$-hexadecane by using the Prigogine-Flory theory mentioned earlier, with experimental values of the excess enthalpy being used to fix the one adjustable parameter. The true value of such analyses is difficult to judge given that there are only five hexane isomers to utilize in mixing experiments and so, some time ago, we elected to carry out a series of measurements using the isomeric octanes, $\mathrm{C}_{8} \mathrm{H}_{18}$, of which there are a total of eighteen, seventeen of which are liquid at room temperature. A

plot comparable to Fig. 5 but involving seven of the more commor octanes is given in Fig. 6 where the equimolar excess voiumes of these octanes mixed in turn with cyclopentane ( $r e f .30$ ) cyclohexane and tetrachloromethane (ref. 31) are illustrated. Once again a common, regular pattern is observed but now plots against the solubility parameter and other intuitively reasonable parameters fail to show regular behaviour.

TABLE 5. Equimolar excess volumes, $\mathrm{V}^{\mathrm{E}}$, for cyclohexane + isomeric octane at $298.15 \mathrm{~K}$ and $\mathrm{Z}$, the coniormational partition function for the octane.

\begin{tabular}{lrr}
\hline Octane & $\mathrm{V}^{\mathrm{E}} / \mathrm{cm}^{3} \mathrm{~mol}^{-1}$ & $\mathrm{Z}$ \\
\hline & & \\
\hline & 0.380 & 14.4 \\
n-octane & 0.267 & 8.0 \\
3-methylheptane & 0.284 & 5.9 \\
4-methylheptane & 0.326 & 6.9 \\
3-ethylhexane & 0.293 & - \\
2,2-dimethylhexane & 0.072 & 11.2 \\
2, 3-dimethylhexane & 0.277 & 7.2 \\
2,4-dimethylhexane & 0.163 & 6.0 \\
2, 5-dimethylhexane & 0.111 & 10.8 \\
3,3-dimethylhexane & 0.281 & 7.4 \\
3,4-dimethylhexane & 0.326 & 7.7 \\
2-methyl, 3-ethylpentane & 0.248 & 7.0 \\
3-methyl, 3-ethylpentane & 0.254 & 8.2 \\
2,2,3-trimethylpentane & 0.183 & 6.68 \\
2,2,4-trimethylpentane & 0.000 & 11.09 \\
2,3,3-trimethylpentane & 0.225 & 5.97 \\
2,3,4-trimethylpentane & 0.209 & 3.83 \\
\hline
\end{tabular}

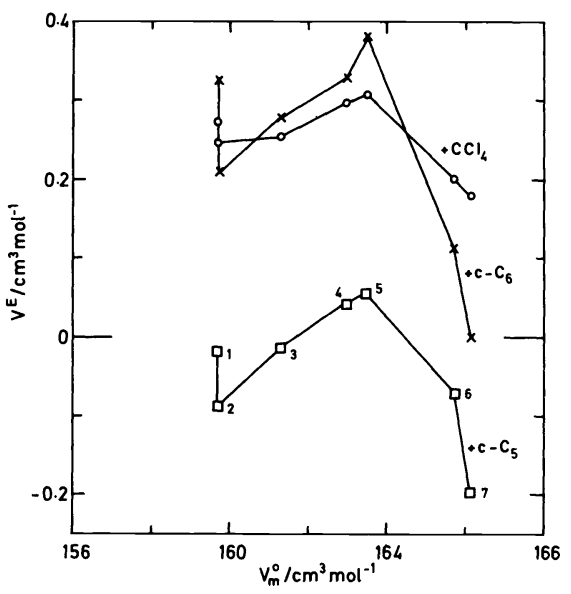

Fig. 6. Equimolar excess volumes at $298.15 \mathrm{~K}$ for mixtures of seven isomeric octanes, 1, 3,4-dimethylhexane; 2 , 2,3,4-trimethylpentane; 3, 2,3-dimethylhexane; 4, 4-methylheptane; 5, n-octane; $6,2,5$-dimethylhexane; $7,2,2,4-\operatorname{tri}-$ methylpentane, mixed with o, tetrachloromethane; $x$, cyclohexane; $\square$, cyclopentane versus $\mathrm{V}_{\mathrm{m}}^{\circ}$, the molar volume of the octanes.

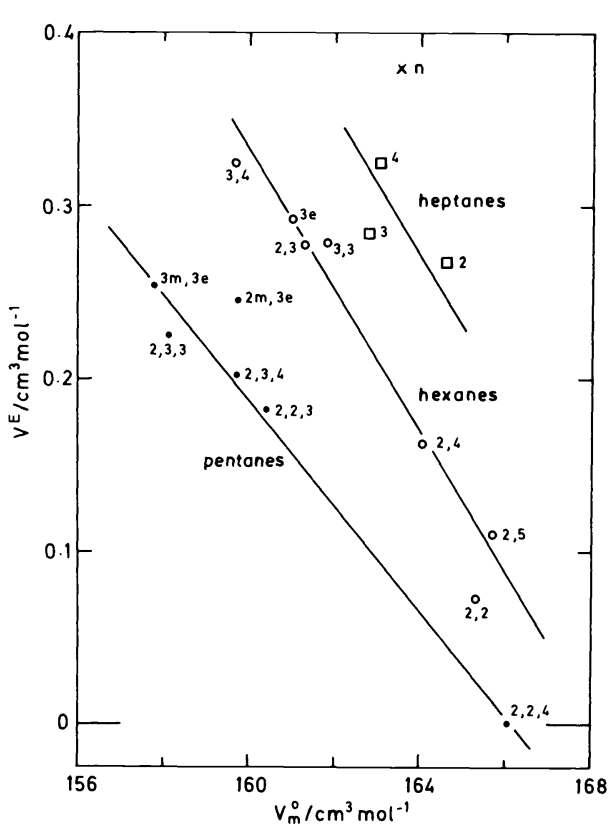

Fig. 7. Equimolar excess volumes at $298.15 \mathrm{~K}$ for mixtures of isomeric octanes with cyclohexane. - substituted pentanes, o substituted hexanes, $\square$ substituted heptanes, $x$ n-octane against $V_{m}^{\circ}$, the molar volume of the octane. 
The full range of data for cyclchexane plus the seventeen isomeric octanes is depicted in Fig. 7 and the equimolar excess volumes are listed in Table 5 . It is seen in Fig. 7 that, on this scale, there is a rough correlation for the mixtures containing the group of six substituted pentanes, the seven hexanes and the three heptanes, with n-octane+cyclohexane exhibiting the most positive value of the excess volume. Excess enthalpies and excess Gibbs functions have been measured for a few of these mixtures (ref. 32) and when the experimental values of the equimolar excess enthalpies are used to adjust the $\xi$ parameter in the Carnahan and Starling equation and excess volumes calculated assuming spherical symmetry, it is found that the predicted order is almost a complete inverse of the experimental, with $\mathrm{V}^{\mathrm{E}}$ for $\mathrm{n}$-octane+cyclohexane now exhibiting the most negative value followed in ascending order, by the heptanes, hexanes and pentanes.

In order to test whether the behaviour of the excess volumes depicted in Fig. 7 was mirrored by other mixing functions, $\mathrm{T}^{\mathrm{c}}$, the upper critical solution temperature of the seventeen octanes mixed with methanol was determined (ref. 33). Such measurements have the advantage or requiring very small amounts of the pure components and the results are illustrated in Fig. 8 where $\mathrm{T}^{\mathrm{C}}$ is plotted against $\mathrm{V}_{\mathrm{m}}^{\circ}$, the molar volume of the octane estimated at the critical temperature $\mathrm{T}^{\mathrm{c}}$. The pattern of behaviour is very similar to that of the excess volumes with only the mixture containing 2-methyl, 3-ethylpentane appearing anomalous.

In an attempt to establish whether the degree of internal rotational motion has a direct influence on the mixing properties, $\mathrm{Z}$, the conformational partition function, first described by Pitzer (ref. 34) was calculated for each octane. The methodology adopted was that of Flory (ref. 35) and of Colle et. al. (ref. 36 ). It was, of course, realised at the outset that this parameter, as defined, represents a property of a single isolated molecule and does not account for the cooperative effects which undoubtedly play a significant rôle in determining the physical properties and structure of the condensed state.

The calculation of $\mathrm{Z}$ involves the assumption that, for a molecule in a particular configuration, the conformational potential energy $\mathrm{E}$ is given by the sum of the energies of $\mathrm{E}_{\text {it }}$, the intrinsic torsional potentials about the carbon-carbon bonds and

$\mathrm{E}_{\mathrm{nb}}$ the non-bonded interactions of atoms or groups separated by more than two $\mathrm{C}-\mathrm{C}$ bonds.

$$
E=E_{i t}+E_{n b}
$$

$E_{n b}$ was calculated by assuming a Lennard-Jones 6-12 potential acting between the relevant groups and numerical values of the Lennard-Jones parameters and for $E_{i t}$ were taken from ref. 35 and ref. 36 . Z, which is a measure of the conformational flexibility is calculated from

$$
\mathrm{Z}=\int \exp \left[\left(\mathrm{E}_{\min }-\mathrm{E}\right) / \mathrm{RT}\right]
$$

where $E_{m i n}$ is the minimum value of $E$ calculated when the molecule has adopted its "most probable configuration", and the integration in equation 7 extends over all angles and all relevant bonds. Rotation about only two bonds need 


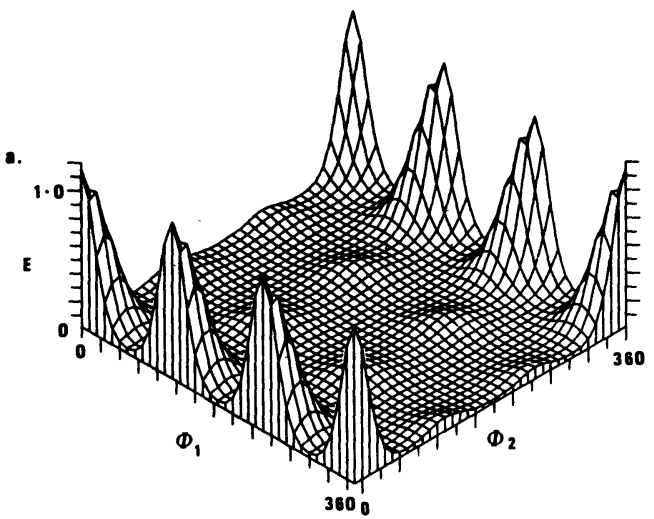

2,2,3-trimethylpentane

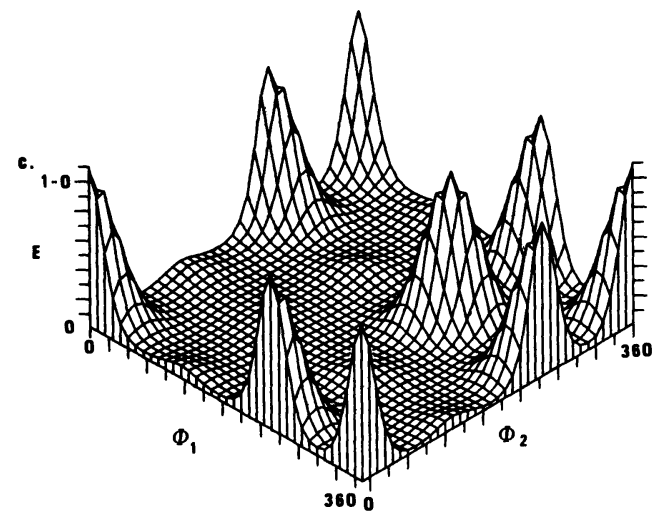

$2,3,4-t r i m e t h y l$ pentane

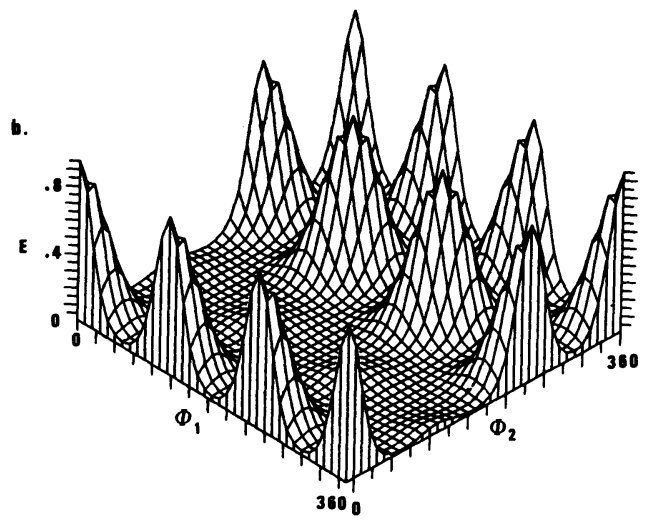

$2,2,4-t r$ imethylpentane

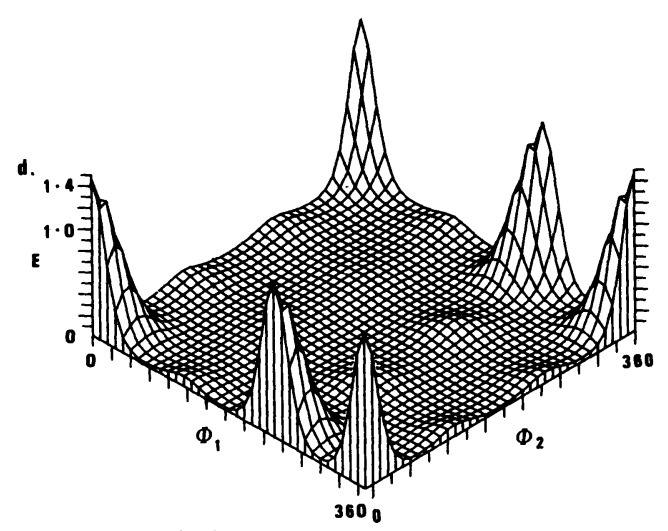

2,3,3-trime thylpentane

Fig. 9. Rotational energy surfaces for the four trimethylpentanes. $E$ is the intramolecular energy in $\mathrm{kJ} \mathrm{mol}^{-1}$, $\phi_{1}$ and $\phi_{2}$ represent the angular distribution about the $\mathrm{C}_{2}-\mathrm{C}_{3}$ and $\mathrm{C}_{3}-\mathrm{C}_{4}$ carbon-carbon bonds respectively.

be considered for the four substituted pentanes and Fig. 9 illustrates the potential energy surface $E=f\left(\phi_{1}, \phi_{2}\right)$ where $\phi_{1}$ and $\phi_{2}$ are the rotational angles about the $\mathrm{C}_{2}-\mathrm{C}_{3}$ and $\mathrm{C}_{3}-\mathrm{C}_{4}$ bonds respectively. An angular increment of one degree was used and the derived $Z$ values for these and the other octanes have been listed, together with the equimolar values of the excess volumes of mixtures with cyclohexane in Table 5 .

The computational difficulties increase as the degree of substitution decreases and four degree rotational increments were used for the hexanes and twelve degrees for the three heptanes to keep the calculations within the limits of the available computer storage capacity. The $Z$ value for $n-$ octane was extrapolated from calculated values for the lower n-alkanes. The derived values of $Z$ depend critically on locating the correct value of $E_{\text {min }}$.

Inspection of Table 5 shows that although there is a partial correlation of excess volume with $\mathrm{Z}$ within a particular sub-group, the pentanes, hexanes, etc., there is no overall correlation within the octanes as a class. This is a not totally unexpected result and it may well be that a fully satisfactory account of such molecules in the liquid state must await a full simulation treatment of flexible molecules. Analyses for the simplest of such molecules are now just within the power of present-day computers and some recent results are discussed elsewhere in the proceedings of this Conference. A full treatment of larger molecules must await the development of either the next computer generation or, more usefully, the production of dedicated, special purpose, simulation computers. Currently, a number of groups in both the USA and Europe are building machines of the latter type. 


\section{REFERENCES}

1. J. S. Rowlinson and F. L. Swinton, Liquids and Liquid Mixtures, 3rd Ed., Butterworth, London (1982).

2. G. Soave, Chem. Eng. Sci., 27, 1197 (1972).

3. D. Peng and D. B. Robinson, Ind. Eng. Chem. Fund., 15, 59 (1978).

4. K. E. Starling and M. S. Han, Hydrocarbon Proc., 52, 107 (1972).

5. R. M. Gibbons in Chemical Thermodynamics in Industry, Vol. 8 of Critical Reports on Applied Chemistry, Ed. T. I. Barry, p.120, Blackwell, Oxford $(1985)$.

6. H. C. Longuet-Higgins and B. Widom, Mol. Phys., 8, 549 (1964);

N. S. Snider and T. M. Herrington, J. Chem. Phys., 47, 2248 (1967).

7. M. L. McGlashan, Trans. Faraday Soc., 66, 18 (1970); K. N. Marsh,

M. L. McGiashan and C. Warr, ibid., 66, 2453 (1970).

8. R. P. Tomlins and K. N. Marsh, J. Chem. Thermodynamics, 9, 651 ( 1977 ).

9. A. Blinowska, T. M. Herrington and L. A. K. Staveley, Cryogenics, 85 $(1973)$.

10. N. F. Carnahan and K. E. Starling, J. Chem. Phys., 51, 635 (1969).

11. D. Patterson, Pure Appl. Chem., 47, 305 (1976).

12. I. Prigogine, The Molecular Theory of Solutions, North-Holland, Amsterdam $(1957)$; P. J. Flory, J. Amer. Chem. Soc., 87, 1833 (1965).

13. A. Fredenslund, J. Gmehling and P. Rasmussen, Vapour Liquid Equilibria using UNIFAC, Elsevier, Amsterdam (1977).

14. K. Kojima and K. Tochigi, Prediction of Vapour-Liquid Equilibria by the ASOG Method, Elsevier, Amsterdam (1979).

15. W. E. Acree, Jr., Thermodynamic Properties of Nonelectrolyte Solutions, Academic Press, Orlando (1984).

16. N. M. D. Brown, J. F. Maguire and F. L. Swinton, Discuss. Faraday Soc., 66,244 (1978).

17. $\bar{M}$. R. Battaglia, T.I. Cox and P. A. Madden, Mol. Phys., 37, 1413 (1979).

18. R. W. Impey, P. A. Madden and D. J. Tildesley, Mol. Phys., 44, 1319 (1981).

19. M. L. McGlashan, D. Stubley and H. Watts, J. Chem. Soc., A, 673 (1969).

20. W. Wóyciçki, J. Chem. Thermodynamics, $\underline{7}, 7 \overline{7}(1975)$; ibid., $\underline{7}, 1007$ (1975).

21. T. Boublik, J. Chem. Phys., 63, 4084 (1975).

22 . I. Nezbeda, Chem. Phys. Lett., 41, 55 (1976).

23. J. Pavlícek, I. Nezbeda and T. Boublik, Czech. J. Phys., B, ¿z9, 1061 (1979).

24. T. Boublik, Coll. Czech. Chem. Comm., 48, 192 (1983).

25. M. Bohn, S. Lago, J. Fischer and F. Kohler, Fluid Phase Equil., 23, 137 $(1985)$.

26. J. Reeder, C. M. Knobler and R. L. Scott, J. Chem. Thermodynamics, ' 7,345 (1975); J. Reeder, T. E. Block and C. M. Knobler, ibid., 8, 133 (1976), Y. P. Handa, C. M. Knobler and R. L. Scott, ibid., $\overline{9}(197 \overline{7})$; G. -K. Zheng, B. M. Schmitter, C. M. Knobler and R. L. Scott, ibid., 16 (1984).

27. S. E. M. Hamam, M. K. Kumaran and G. C. Benson, J. Chem. Thermodynamics, $16,537(1984)$.

28. F. Kimura and G. C. Benson, J. Chem. Eng. Data, 29, 72 (1984).

29. H. Tra Van and D. Patterson, J. Solution Chem., 11,793 (1982).

30. J. S. Hrennan, R. J. Hill and F. L. Swinton, J. Chem. Thermodynamics, 10, $169(1978)$.

31. D. Anderson, D.Phil. Thesis, New University of Ulster (1983).

32. T. E. Mairs and F. L. Swinton, J. Chem. Thermodynamics, 12, 575 (1980);

R. J. Hill, T. E. Mairs and F. L. Swinton, ibid., 12, $58 \overline{1}(1980)$.

33. H. Flanagan, B.Sc. Thesis, New University of Ulster (1983).

34. K. S. Pitzer, J. Chem. Phys., 8, 711 (1940).

35. P. J. Flory, Statistical Mechañics of Chain Molecules, Chapter 3 , Interscience, New York (1969).

36. R. Colle, U. W. suter and P. L. Luisi, Tetrahedron, 37, 3727 (1981). 